Article

\title{
Probiotic Ferulic Acid Esterase Active Lactobacillus fermentum NCIMB 5221 APA Microcapsules for Oral Delivery: Preparation and in Vitro Characterization
}

Catherine Tomaro-Duchesneau ${ }^{1}$, Shyamali Saha ${ }^{2}$, Meenakshi Malhotra ${ }^{1}$, Michael Coussa-Charley ${ }^{1}$, Imen Kahouli ${ }^{3}$, Mitchell L. Jones ${ }^{4}$, Alain Labbé ${ }^{4}$ and Satya Prakash ${ }^{1, *}$

1 Biomedical Technology and Cell Therapy Research Laboratory, Departments of Biomedical Engineering, Physiology, and Artificial Cells and Organs Research Center, Faculty of Medicine, McGill University, 3775 University Street, Montreal, Quebec, H3A 2B4, Canada;

E-Mails: catherine.tomaro-duchesneau@mail.mcgill.ca (C.T.-D.); meenakshi.malhotra@mail.mcgill.ca (M.M.); michael.coussa-charley@mail.mcgill.ca (M.C.-C.)

2 Faculty of Dentistry, McGill University, 3775 University Street, Montreal, Quebec, H3A 2B4, Canada; E-Mail: shyamali.saha@mail.mcgill.ca

3 Department of Experimental Medicine, McGill University, 3775 University Street, Montreal, Quebec, H3A 2B4, Canada; E-Mail: imen.kahouli@mail.mcgill.ca

4 Micropharma Limited, 141 President Kennedy Ave., UQAM Biological Sciences Building, 5th Floor, Suite 5569, Montreal, Quebec, H2X 3Y7, Canada;

E-Mails: mitchell@micropharma.net (M.L.J.); alain@micropharma.net (A.L.)

* Author to whom correspondence should be addressed; E-Mail: satya.prakash@mcgill.ca; Tel.: +1-514-398-3676; Fax: +1-514-398-7461.

Received: 23 December 2011; in revised form: 3 February 2012 / Accepted: 10 February 2012 / Published: 16 February 2012

\footnotetext{
Abstract: Probiotics possess potential therapeutic and preventative effects for various diseases and metabolic disorders. One important limitation for the oral delivery of probiotics is the harsh conditions of the upper gastrointestinal tract (GIT) which challenge bacterial viability and activity. One proposed method to surpass this obstacle is the use of microencapsulation to improve the delivery of bacterial cells to the lower GIT. The aim of this study is to use alginate-poly-L-lysine-alginate (APA) microcapsules to encapsulate Lactobacillus fermentum NCIMB 5221 and characterize its enzymatic activity and viability through a simulated GIT. This specific strain, in previous research, was characterized for its inherent ferulic acid esterase (FAE) activity which could prove beneficial in the
} 
development of a therapeutic for the treatment and prevention of cancers and metabolic disorders. Our findings demonstrate that the APA microcapsule does not slow the mass transfer of substrate into and that of the FA product out of the microcapsule, while also not impairing bacterial cell viability. The use of simulated gastrointestinal conditions led to a significant $2.5 \log$ difference in viability between the free $\left(1.10 \times 10^{4} \pm 1.00 \times 10^{3} \mathrm{cfu} / \mathrm{mL}\right)$ and the microencapsulated $\left(5.50 \times 10^{6} \pm 1.00 \times 10^{5} \mathrm{cfu} / \mathrm{mL}\right)$ L. fermentum NCIMB 5221 following exposure. The work presented here suggests that APA microencapsulation can be used as an effective oral delivery method for L. fermentum NCIMB 5221, a FAE-active probiotic strain.

Keywords: Lactobacillus fermentum; artificial cells; ferulic acid esterase; microcapsules

\section{Introduction}

Ferulic acid (FA), a naturally found phenolic acid, is a potent antioxidant able to neutralize free radicals, such as Reactive Oxygen Species (ROS) [1]. ROS have been implicated in DNA damage, cancer and accelerated cell aging [2]. Recent studies suggest that FA has antitumor activity against breast cancer [3,4] liver cancer [5,6] and is effective at preventing cancer induced by the exposure to various carcinogenic compounds such as benzopyrene [7] and 4-nitroquinoline 1-oxide [8]. The oral delivery of free FA is hampered by its quick absorption in the small intestine, specifically in the jejunum, followed by its rapid excretion $[9,10]$. However, it has been proposed, and shown in previous studies that some GIT bacterial strains produce FAE, an enzyme that has the inherent capability to produce FA from available substrates in the GIT (see Figure 1).

Figure 1. Ferulic acid esterases (FAE) enable microbes to hydrolyse the ester bond between hydroxyl cinnamic acids and sugars. The hydrolysis of ethyl ferulate by FAE gives rise to ferulic acid a compound with a number of health-promoting benefits.

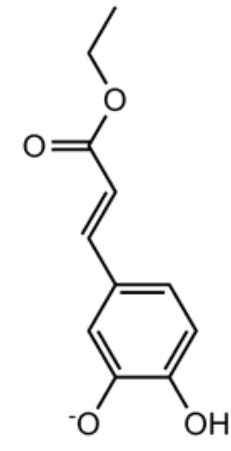

Ethyl ferulate

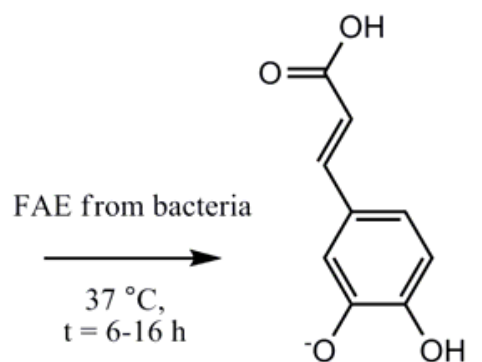

Ferulic acid

The oral delivery of conjugated FA, in the form of a dietary source such as wheat bran, is a feasible alternative, with the release of free FA by microbial FAE present in the lower human digestive tract, giving rise to a constant and controlled release of FA $[9,10]$. The development of probiotic 
formulations to enhance the FA bioavailability should prove beneficial for the treatment and prevention of inflammatory metabolic disorders [11].Previous research by our group has demonstrated the use of Lactobacillus fermentum NCIMB 5221 as a superior microbial producer of FA [12]. The oral delivery of probiotics, however, is impeded by the harsh conditions of the upper GIT, specifically the presence of bile and a detrimentally acidic $\mathrm{pH}$ [13]. Microencapsulation, a method defined as the "entrapment of a compound or a system inside a dispersed material for its immobilization, protection, controlled release, structuration and functionalisation" has been used to overcome the challenge of delivering bacterial cells through the GIT [14]. This article investigates the use of APA microencapsulation for the viable delivery of the FAE active Lactobacillus fermentum NCIMB 5221 to the colon. The results should demonstrate the efficiency of APA microcapsules to increase the viability of this specific probiotic strain in the GIT while preserving enzymatic activity in terms of FA production.

\section{Experimental Methods and Materials}

\subsection{Bacterial Growth Media and Chemicals}

Ethyl ferulate (ethyl 4-hydroxy-3-methoxycinnamate, EFA) and ferulic acid (trans-4-hydroxy-3methoxycinnamate, FA) were purchased from Sigma-Aldrich (Oakville, ON, Canada). De Man, Rogosa, Sharpe (MRS) broth and Methanol of high-performance liquid chromatography (HPLC) grade were obtained from Fisher Scientific (Ottawa, ON, Canada). Water was purified with an EasyPure reverse osmosis system and a NanoPure Diamond Life Science (UV/UF) ultrapure water system from Barnstead (Dubuque, IA, USA). All other chemicals were of analytical or HPLC grade and purchased from commercial sources.

\subsection{Bacterial Strains and Culture Conditions}

Lactobacillus fermentum NCIMB 5221 was purchased from NCIMB (Aberdeen, Scotland, UK). The bacterial strain was stored at $-80{ }^{\circ} \mathrm{C}$ in MRS containing $20 \%$ (v/v) glycerol. An MRS-agar plate was streaked for isolation from the frozen stock and incubated at $37{ }^{\circ} \mathrm{C}$ with $5 \% \mathrm{CO}_{2}$ for $24 \mathrm{~h}$ to ensure purity. One colony from the MRS-agar plate was inoculated into $5 \mathrm{~mL}$ of MRS broth and incubated at $37^{\circ} \mathrm{C}$ for $24 \mathrm{~h}$. A $1 \%(\mathrm{v} / \mathrm{v})$ inoculum was then used for subculturing and incubated at $37^{\circ} \mathrm{C}$ for $24 \mathrm{~h}$ immediately before use.

\subsection{APA Microencapsulation}

The microencapsulation of L. fermentum NCIMB 5221 was performed according to the standard protocol, with slight modifications to the flow rate, vibration frequency and voltage [15]. The microcapsules were loaded with $8 \%(\mathrm{w} / \mathrm{v})$ bacterial pellet. A sodium-alginate solution $(1.75 \% \mathrm{w} / \mathrm{v})$ containing the L. fermentum NCIMB 5221 was extruded into a stirred $\mathrm{CaCl}_{2}$ solution $(0.1 \mathrm{M})$ using a microencapsulator and a $200 \mu \mathrm{m}$ nozzle (Inotech Corp.). The formed calcium-alginate beads were washed in a physiological solution (PS) followed by their immersion in a poly-L-lysine (PLL) solution $(0.1 \% \mathrm{w} / \mathrm{v})$ for $20 \mathrm{~min}$. Another wash in PS was performed for $5 \mathrm{~min}$ followed by immersion in a sodium-alginate solution $(0.1 \% \mathrm{w} / \mathrm{v})$ for $20 \mathrm{~min}$. The resulting microcapsules were stored in minimal 
storage media at $4{ }^{\circ} \mathrm{C}$ for further testing. Viability on microcapsules was performed by exposure to $0.1 \mathrm{M}$ sodium citrate until disruption of the microcapsule was observed. Ten-fold serial dilutions in physiological saline followed by plating on MRS-agar plates were then performed to determine the colony forming units.

\subsection{Ferulic Acid Esterase HPLC Assay To Measure FA Production}

The bacterial strain was subcultured from MRS broth at $1 \%(\mathrm{v} / \mathrm{v})$ to MRS-EFA broth at an EFA concentration of $1.33 \mathrm{mM}(0.2956 \mathrm{mg} / \mathrm{mL})$. For the APA microcapsules these were added at $10 \%(\mathrm{w} / \mathrm{v})$ into MRS-EFA broth. Uninoculated MRS-EFA broth was used as a negative control and treated in the exact same way. Each sample was treated in triplicate and incubated at $37{ }^{\circ} \mathrm{C}$ during the course of the experiment. An HPLC assay, modified from Mastihuba et al., was used to measure FAE activity [16]. At each time point, $500 \mu \mathrm{L}$ of sample was added to tubes and centrifuged at 10,000 rpm for $7 \mathrm{~min}$ at $4{ }^{\circ} \mathrm{C}$. The resulting supernatant $(300 \mu \mathrm{L})$ was acidified with $0.35 \mathrm{M} \mathrm{H}_{2} \mathrm{SO}_{4}(100 \mu \mathrm{L})$ and vortexed. $1 \mathrm{mM}$ benzoic acid $(300 \mu \mathrm{L})$ was added, as an internal standard, followed by the addition of $0.7 \mathrm{M} \mathrm{NaOH}(100 \mu \mathrm{L})$ to neutralize the $\mathrm{pH}$. The samples were then stored at $-20{ }^{\circ} \mathrm{C}$ until all of the samples were collected for the HPLC analysis.

For HPLC analysis, the samples were thawed to room temperature and filtered with a $0.45 \mu \mathrm{m}$ filter. The analysis was performed on a reverse-phase C-18 column: LiChrosorb RP-18, $25 \times 0.46 \mathrm{~cm}$ (Grace Davison Discovery Sciences, ON, Canada). The HPLC system consists of a ProStar 335 diode array detector (DAD) set at $280 \mathrm{~nm}$ and $320 \mathrm{~nm}$, a ProStar 410 autosampler, and the software Star LC workstation version 6.41. $25 \mu \mathrm{L}$ was injected for each sample. The mobile phase (solvent A) consists of $37 \%(\mathrm{v} / \mathrm{v})$ methanol and $0.9 \%(\mathrm{v} / \mathrm{v})$ acetic acid in water (HPLC grade). Solvent B consisted of $100 \%(\mathrm{v} / \mathrm{v})$ methanol. The run was initiated with solvent $\mathrm{A}$ at $100 \%$ for 16 minutes. This was followed by a 1 minute linear gradient to reach $100 \%$ of solvent B, attained at the 17 th minute. Solvent B was isocratically held at $100 \%$ for 12 minutes, until the 29th minute. This was followed by a 1 minute linear gradient to reach $100 \%$ of solvent A by the 30th minute. Standard curves of FA and EFA, using peak area quantification, were generated for quantifying the test sample FA and EFA concentrations. The FA standard curve was generated using triplicates and the concentrations 100, 300, 500, 960 and $1,100 \mu \mathrm{M}$ were plotted against peak area $\left(\mathrm{R}^{2}=0.9869\right)$. The EFA standard curve was generated using triplicates and the concentrations $100,300,500,700,1,000,1,400$ and 1,800 $\mu \mathrm{M}$ were plotted against peak area $\left(\mathrm{R}^{2}=0.9785\right)$. Standards and quality control samples were prepared and analyzed in the same way as the test samples.

\subsection{Simulated Gastrointestinal Conditions to Determine the Stability and Viability of Microencapsulated L. Fermentum NCIMB 5221 Delivered Orally}

Simulated gastric (SGF) and intestinal fluids (SIF) were prepared according to the U.S. Pharmacopeia, with some minor modifications [17]. SGF consisted of $\mathrm{NaCl}(2 \mathrm{~g} / \mathrm{L})$, glucose $(3.5 \mathrm{~g} / \mathrm{L})$ and pepsin $(3.2 \mathrm{~g} / \mathrm{L})$ in deionized water. The $\mathrm{pH}$ of the SGF was adjusted to $1.5 \mathrm{using} 2 \mathrm{M} \mathrm{HCl}$. SIF consisted of monobasic potassium phosphate $(6.8 \mathrm{~g} / \mathrm{L})$, pancreatin $(10 \mathrm{~g} / \mathrm{L})$, Oxgall $(1.5 \mathrm{~g} / \mathrm{L})$ and glucose $(3.5 \mathrm{~g} / \mathrm{L})$ in deionized water. $20 \mathrm{~g}$ of APA microcapsules or $2 \mathrm{~g}$ of free L. fermentum NCIMB 5221 were added to $200 \mathrm{~mL}$ SGF and incubated at $37{ }^{\circ} \mathrm{C}$ on a rotary shaker at $75 \mathrm{rpm}$ for $2 \mathrm{~h}$. Following the $2 \mathrm{~h}$, 
$200 \mathrm{~mL}$ of SIF was added into each flask and the $\mathrm{pH}$ was increased to 6.8 using $2 \mathrm{M} \mathrm{NaOH}$. At each time point, $1 \mathrm{~mL}$ of the solution was sampled into $9 \mathrm{~mL}$ of $0.1 \mathrm{M}$ sodium citrate. This was serially diluted in 10 -fold dilutions in $0.85 \%(\mathrm{w} / \mathrm{v}) \mathrm{NaCl}$ and plated on MRS agar in triplicates. These MRS-agar plates were incubated at $37{ }^{\circ} \mathrm{C}$ and $5 \% \mathrm{CO}_{2}$, followed by colony counting following $48 \mathrm{~h}$ of incubation.

\subsection{Statistical Analysis}

Values are expressed as means \pm Standard Deviation. Statistical analysis was carried out using Minitab (Minitab, Version 14, Minitab Inc., State College, PA, USA). Statistical comparisons between EFA/FA concentrations were carried out by using the general linear model (GLM) and post-hoc analysis. Statistical significance was set at $p<0.05$. All interaction terms were treated as fixed terms and $p$-values less than 0.01 were considered highly significant.

\section{Results and Discussion}

\subsection{Results}

L. fermentum NCIMB 5221 microcapsules were formed to investigate the suitability of the APA microcapsule for the oral delivery of an FAE active probiotic. L. fermentum NCIMB 5221 microencapsulation was optimized - by controlling the flow rate, stirring time, stirring speed, coating time, vibration frequency, and voltage - to obtain monodispersed and spherical microcapsules. The obtained microcapsules were observed under light microscopy at magnifications of $40 \times, 100 \times$ and $200 \times$. The APA microcapsules obtained were monodispersed, as seen in Figure 2A, with an approximate size of $400 \pm 25 \mu \mathrm{m}$ in diameter. Figure $2 \mathrm{~B}$ demonstrates the spherical shape of the microcapsules and Figure $2 \mathrm{C}$ allows for visualisation of the outer coat of the APA microcapsule loaded with L. fermentum NCIMB 5221 at $8 \%$ of the total microcapsule weight. The viability of the bacteria prior to microencapsulation, in the alginate solution, was determined to be $1.95 \times 10^{9} \pm 2.1 \times 10^{8} \mathrm{cfu} / \mathrm{mL}$ and the microcapsules had a final viability of $1.21 \times 10^{9} \pm 9.54 \times 10^{7} \mathrm{cfu} / \mathrm{g}$, suggesting no significant loss of bacterial viability due to the process of APA microencapsulation.

Figure 2. Morphology of APA microcapsule containing L. fermentum NCIMB 5221 taken by light microscope (A) $40 \times$ (B) $100 \times$ (C) $200 \times$. The approximate diameter of the microcapsules was $400 \pm 25 \mu \mathrm{m}$.
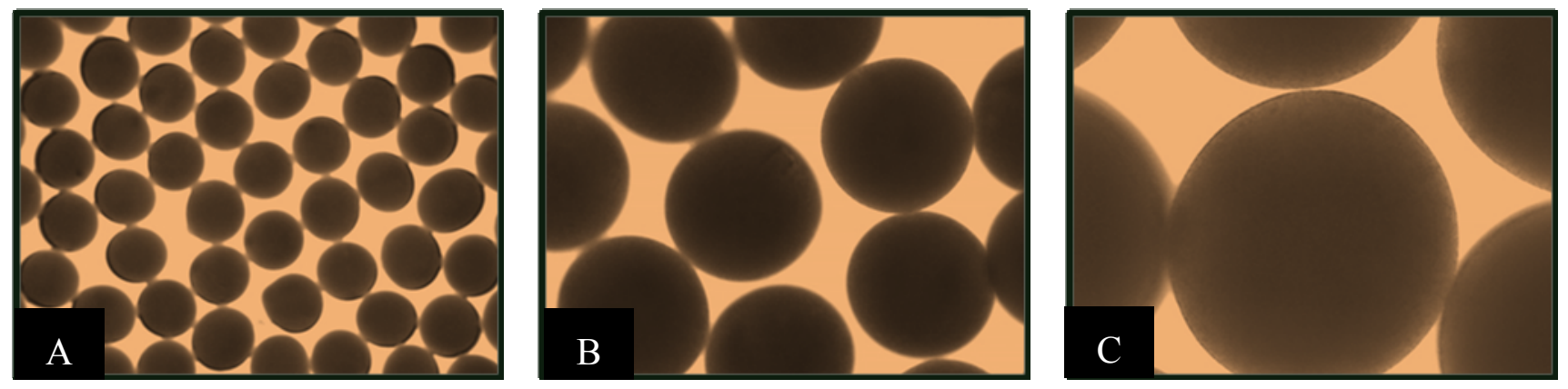

The FAE activity of APA microencapsulated L. fermentum NCIMB 5221 was then determined to ensure that the APA microcapsule does not impede the uptake of the substrate, EFA, and the release of 
the desired product, FA. For this, the viability of free and microencapsulated L. fermentum NCIMB 5221 during the FAE assay was determined, as can be observed in Figure 3.

Figure 3. The viability of the free and microencapsulated L. fermentum NCIMB 5221 during the FAE assay (MRS-EFA $0.2956 \mathrm{mg} / \mathrm{mL}$ at $37^{\circ} \mathrm{C}$ ). Each point represents the mean of triplicates and the error bars the standard deviation. During the assay, there was no significant difference in viability between the free and microencapsulated bacteria.

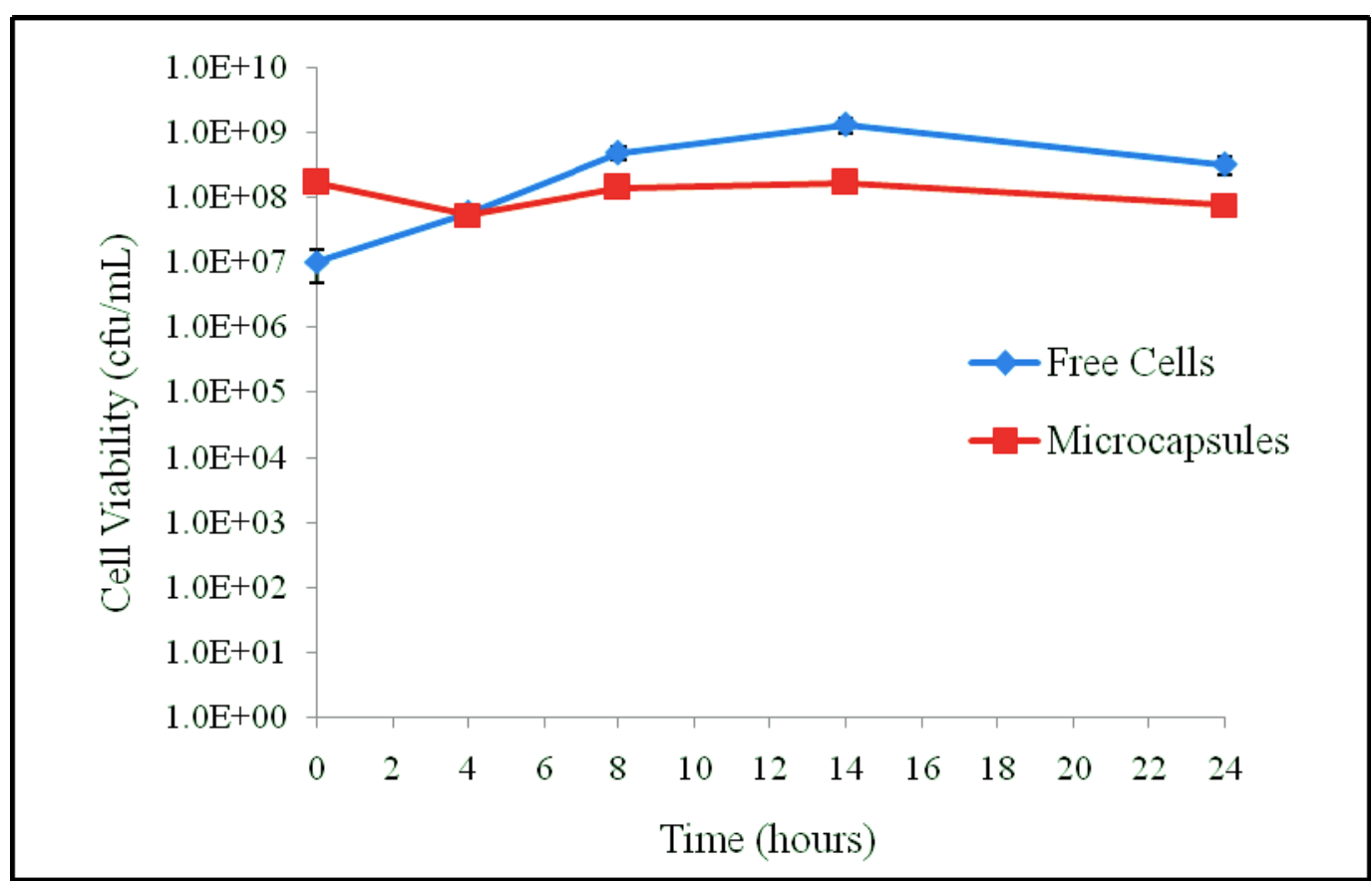

At the start of the assay, the free cells had a viability of $1.53 \times 10^{9} \pm 9.02 \times 10^{7} \mathrm{cfu} / \mathrm{mL}$ and the microcapsules a viability of $6.77 \times 10^{8} \pm 7.77 \times 10^{7} \mathrm{cfu} / \mathrm{mL}$. Following $24 \mathrm{~h}$ of incubation, the free cells had a viability of $3.27 \times 10^{8} \pm 1.00 \times 10^{3} \mathrm{cfu} / \mathrm{mL}$ and the microcapsules a viability of $7.72 \times 10^{7} \pm 1.00 \times 10^{5} \mathrm{cfu} / \mathrm{mL}$.

In terms of FAE activity, the initial EFA concentration was $0.2956 \mathrm{mg} / \mathrm{mL}$. Following $30 \mathrm{~h}$ of incubation, the free cells had $0.0382 \pm 0.0011 \mathrm{mg} / \mathrm{mL}(12.92 \pm 0.37 \%)$ and the microcapsules had $0.057 \pm 0.0054 \mathrm{mg} / \mathrm{mL}(19.28 \pm 1.83 \%)$ EFA remaining in solution, as seen in Figure 4A. At this point, the free cells had a total production of $0.1872 \pm 0.0033 \mathrm{mg} / \mathrm{mL}$ FA and APA microcapsules had a final production of $0.1760 \pm 0.0149 \mathrm{mg} / \mathrm{mL}$ FA, as seen in Figure 4B.

The viability of L. fermentum NCIMB 5221 in free and encapsulated form was determined upon exposure to the simulated gastrointestinal conditions, Figure 5. The initial viability of L. fermentum NCIMB 5221 was $1.53 \times 10^{9} \pm 9.02 \times 10^{7} \mathrm{cfu} / \mathrm{mL}$ for the free cells and $6.77 \times 10^{8} \pm 7.77 \times 10^{7} \mathrm{cfu} / \mathrm{mL}$ for the microencapsulated cells. Following $2 \mathrm{~h}$ of exposure to the simulated conditions of the stomach the viability was $2.60 \times 10^{8} \pm 1.22 \times 10^{8} \mathrm{cfu} / \mathrm{mL}$ for the free cells and $4.73 \times 10^{8} \pm 4.93 \times 10^{7} \mathrm{cfu} / \mathrm{mL}$ for the encapsulated cells. Following the further exposure to simulated intestinal conditions for $24 \mathrm{~h}$, the free L. fermentum NCIMB 5221 demonstrated a viability of $1.10 \times 10^{4} \pm 1.00 \times 10^{3} \mathrm{cfu} / \mathrm{mL}$ and the microencapsulated $L$. fermentum NCIMB 5221 had a viability of $5.50 \times 10^{6} \pm 1.00 \times 10^{5} \mathrm{cfu} / \mathrm{mL}$. The viability of L. fermentum NCIMB 5221, through the in vitro gastrointestinal passage, and the associated conditions of the gastric and intestinal exposure, are summarized in Table 1. It is also noted 
that, following the transition to the intestinal conditions, the microcapsules lost some of their integrity due to a change in $\mathrm{pH}$ and osmotic conditions.

Figure 4. FAE quantitative HPLC assay of free (free L.f. 5221) and microencapsulated L. fermentum NCIMB 5221 (APA L.f. 5221). Uninoculated MRS-EFA was used as a negative control. The presented data represents the amount of unhydrolysed EFA remaining in solution (A) and the amount of FA produced (B), as measured by HPLC peak area data. Each point represents the mean of triplicates and the error bars represent the standard deviations. These results demonstrate no significant difference in FA production between the free and encapsulated L. fermentum NCIMB 5221.

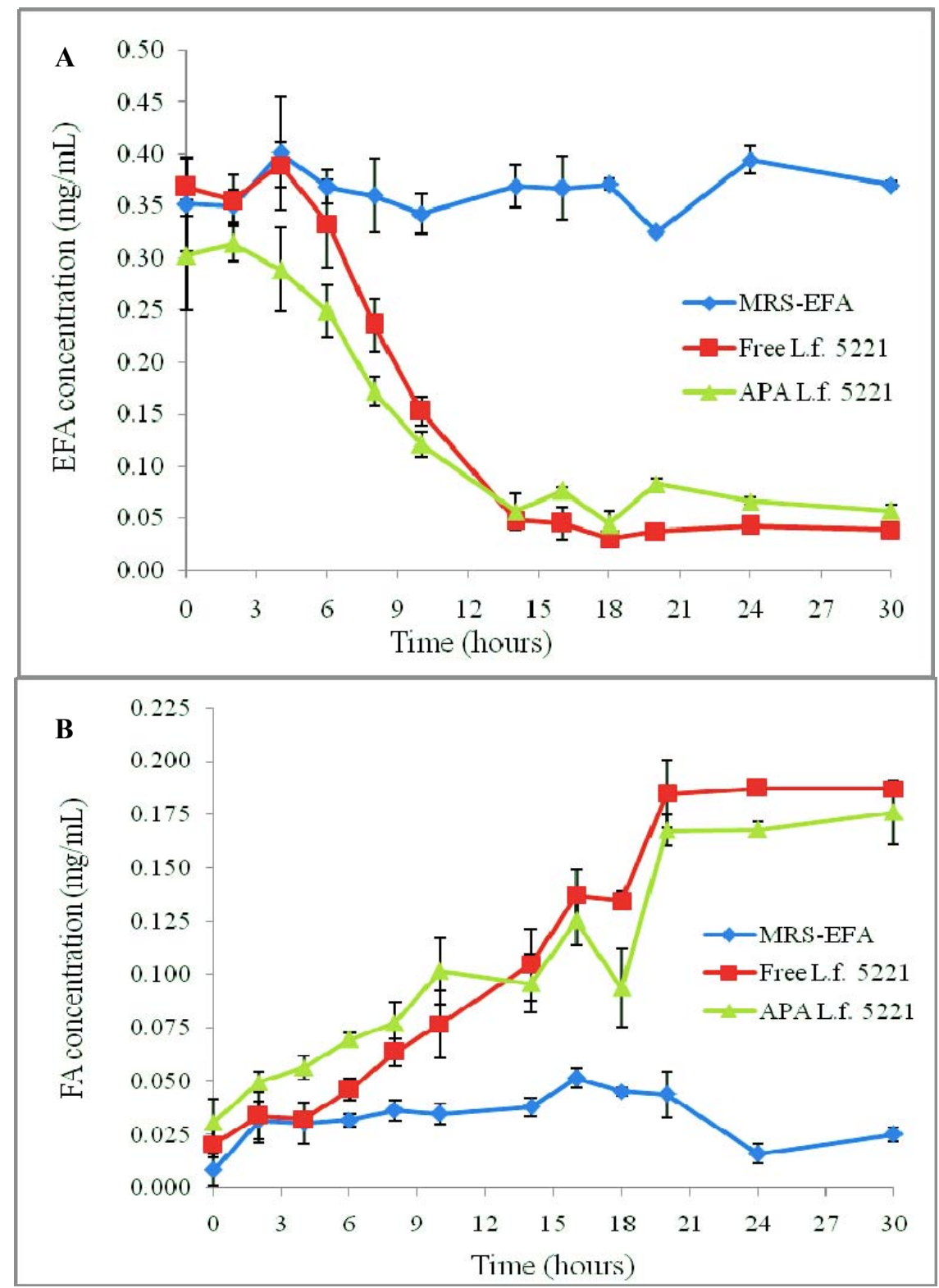


Figure 5. The viability of $L$. fermentum NCIMB 5221 in free and encapsulated form was determined upon exposure to the simulated GI conditions using standard colony counting methods. Each point represents the mean of triplicates and the error bars the standard deviations. A significant difference in viability between free and microencapsulated bacterial cells following simulated GI exposure was observed ( $p<0.001$; Tukey's HSD).

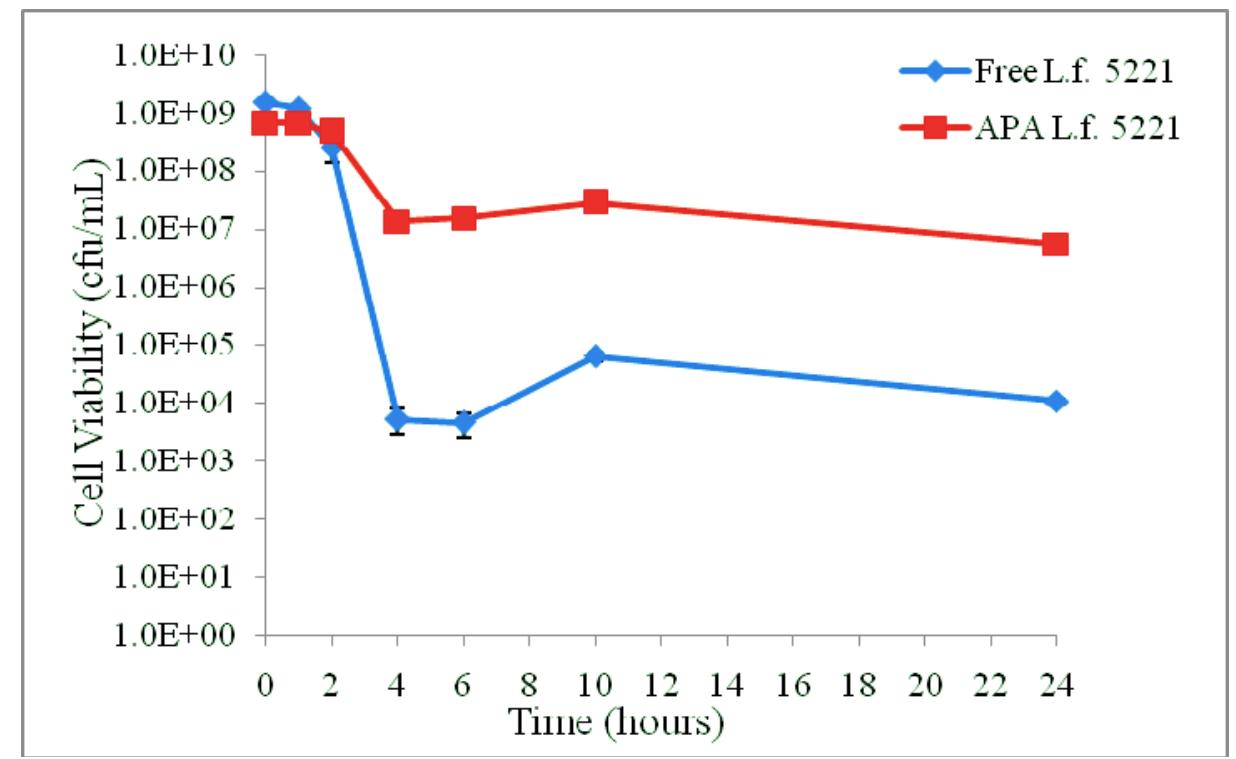

Table 1. The viability of L. fermentum NCIMB 5221, through the in vitro GI passage and the associated conditions of the gastric and intestinal exposure. Free $=$ free L. fermentum NCIMB 5221; APA = microencapsulated L. fermentum NCIMB 5221. The data values represent the mean of triplicates $\pm \mathrm{SD}$. These results demonstrate a significant difference in viability between the free and microencapsulated cells ( $p<0.001$; Tukey's HSD).

\begin{tabular}{|c|c|c|c|c|c|c|c|}
\hline \multirow{2}{*}{$\begin{array}{l}\text { Time } \\
\text { (hours) }\end{array}$} & \multirow{2}{*}{$\begin{array}{c}\text { GIT } \\
\text { section }\end{array}$} & \multirow[t]{2}{*}{ pH } & \multirow[t]{2}{*}{ Solutes } & \multicolumn{2}{|c|}{$\begin{array}{l}\text { Viability } \\
\text { (cfu/mL) }\end{array}$} & \multicolumn{2}{|c|}{$\begin{array}{c}\text { Viability } \\
(\%)\end{array}$} \\
\hline & & & & Free & APA & Free & APA \\
\hline 0 & \multirow[b]{3}{*}{ Stomach } & \multirow[b]{3}{*}{1.5} & \multirow{3}{*}{$\begin{array}{c}\text { Sodium } \\
\text { chloride } \\
\text { Peptic } \\
\text { enzymes } \\
\text { Glucose }\end{array}$} & $1.53 \times 10^{9} \pm 9.02 \times 10^{7}$ & $6.77 \times 10^{8} \pm 7.77 \times 10^{7}$ & $100.00 \pm 0.059$ & $100.00 \pm 0.115$ \\
\hline 1 & & & & $1.18 \times 10^{9} \pm 2.04 \times 10^{8}$ & $6.83 \times 10^{8} \pm 4.51 \times 10^{7}$ & $77.51 \pm 13.365$ & $100.99 \pm 6.664$ \\
\hline 2 & & & & $2.60 \times 10^{8} \pm 1.22 \times 10^{8}$ & $4.73 \times 10^{8} \pm 4.93 \times 10^{7}$ & $17.03 \pm 7.969$ & $69.95 \pm 7.290$ \\
\hline 4 & \multirow{4}{*}{$\begin{array}{c}\text { Small / } \\
\text { Large } \\
\text { intestines }\end{array}$} & \multirow{4}{*}{6.8} & \multirow{4}{*}{$\begin{array}{c}\text { Potassium } \\
\text { phosphate } \\
\text { Pancreatic } \\
\text { enzymes } \\
\text { Bile } \\
\text { Glucose }\end{array}$} & $5.33 \times 10^{3} \pm 2.52 \times 10^{3}$ & $1.35 \times 10^{7} \pm 1.12 \times 10^{6}$ & $0.0004 \pm 0.0002$ & $2.00 \pm 0.165$ \\
\hline 6 & & & & $4.67 \times 10^{3} \pm 2.08 \times 10^{3}$ & $1.53 \times 10^{7} \pm 1.15 \times 10^{6}$ & $0.0003 \pm 0.0001$ & $2.26 \pm 0.170$ \\
\hline 10 & & & & $6.37 \times 10^{4} \pm 1.33 \times 10^{4}$ & $2.82 \times 10^{7} \pm 1.23 \times 10^{6}$ & $0.0042 \pm 0.0009$ & $4.17 \pm 0.182$ \\
\hline 24 & & & & $1.10 \times 10^{4} \pm 1.00 \times 10^{3}$ & $5.50 \times 10^{6} \pm 1.00 \times 10^{5}$ & $0.0007 \pm 0.0001$ & $0.813 \pm 0.015$ \\
\hline
\end{tabular}




\subsection{Discussion}

Past and recent research has looked at probiotics for use as therapeutics. These formulations are defined as dietary supplements containing bacteria which, when administered in adequate amounts, confer a health benefit on the host $[13,18,19]$. Probiotics, as natural compounds, are generally considered safe, but can also be tested for set-out safety parameters [20]. A number of studies have investigated bacterial strains for a range of conditions, including infections, allergies and metabolic disorders such as ulcerative colitis and Crohn's disease [21-25]. Promising research focuses on the microbial secretion and production of beneficial biologically active enzymes and proteins [26,27]. These include the use of ornithine decarboxylase as a powerful antioxidant for the treatment of autoimmune diseases and accelerated cell apoptosis [28], the use of bile salt hydrolase for hypercholesterolemia [29-31], and the use of bile transport and tolerance proteins for the efficient delivery of probiotics [32]. In recent studies, the products of, another microbial protein, cinnamoyl esterase, have shown significant levels of antioxidant activity [12,33] and other effects, including stimulation of insulin secretion [34,35], prevention of oxidative stress [33], lipid peroxidation [36], cholesterol-lowering capabilities [11] and inhibition of diabetic nephropathy progression [37]. FA, a well-characterised antioxidant, is one of the desired products of hydrolysis by FAE [12].

Previously we have screened strains for FAE activity and selected L. fermentum NCIMB 5221 as the best FA producer of the investigated Lactobacilli strains [12]. For the development of an efficient probiotic therapeutic formulation there is a requirement for a carrier system. The delivery of bacterial cells through the GIT is impaired by the harsh conditions of the upper GIT. Microencapsulation, specifically APA has been suggested as a method to overcome this obstacle [13]. This method is investigated in the presented research, specifically with relation to L. fermentum NCIMB 5221 and its FA producing capabilities.

This work investigated the FA production of L. fermentum NCIMB 5221 in both the microencapsulated and the free form. The FAE activity of L. fermentum NCIMB 5221 free and encapsulated was determined by HPLC, to ensure that the microcapsule does not hamper the flow of substrate into and the FA product out of the microcapsule. Cell viability was determined during the assay to ensure that the cell count remained equal. Although FA production was non-significantly higher for free cells, this is explained by slightly higher free cell viability during the course of the experiment Figure 3. This is supported by the previous research that directly correlates bacterial cell counts of L. fermentum NCIMB 5221 with its FA production [12]. Keeping this in mind, the higher the cell count delivered to the colon, the higher the FA production. The successful delivery requires a carrier method such as microencapsulation.

Research has previously been presented on the use of microencapsulated cells for FA production, but fails to demonstrate a comparison between free and microencapsulated bacterial cells under the same conditions, as investigated in the presented research [38]. In terms of microencapsulation technology for the storage of microcapsules, Kailasapathy has demonstrated a significant increase in viability of microencapsulated cells in yoghurt cultures stored over 7 weeks, at a pH as low as 4 [39]. However, in terms of oral delivery, a $\mathrm{pH}$ of approximately 1.5 is encountered in the stomach. Hence, a microcapsule capable of delivering optimal numbers of bacteria through the GIT needs to sustain viability at such a low $\mathrm{pH}$. In this flask study, the exposure to the simulated gastrointestinal conditions 
clearly illustrates the requirement for a carrier system when delivering live bacterial cells to the lower GIT Figure 5. A significant $2.5 \mathrm{log}$ difference in viability following exposure to the simulated conditions could be detected between the free $1.10 \times 10^{4} \pm 1.00 \times 10^{3} \mathrm{cfu} / \mathrm{mL}$ and the microencapsulated $5.50 \times 10^{6} \pm 1.00 \times 10^{5}$ L. fermentum NCIMB 5221 .

Work is being undertaken to determine the FAE activity of free vs. microencapsulated L. fermentum NCIMB 5221 under GIT conditions. Unfortunately, the simple substrate EFA is labile under the enzymatic and $\mathrm{pH}$ conditions used in this study, which quickly resulted in EFA degradation when added to the SGF and SIF solutions. Normally, in the diet, the FA substrate would be present in a more complex form, such as wheat bran, which would permit FA release in the colon due to fermentation processes. This type of food matrix, however, is undefined, rendering it difficult to quantify the low levels of FA that are released. Our research continues to explore the enzymatic process, looking at other in vitro and, potentially, in vivo methods to comprehend the FAE activity in the GIT.

\section{Conclusions}

This work supports the use of APA microencapsulation for the oral delivery of the investigated probiotic. The presented work successfully demonstrated the advantage of using APA microencapsulation for L. fermentum NCIMB 5221 for use in oral delivery. The FAE enzymatic activity and bacterial viability were maintained post-encapsulation and the viability of encapsulated cells was greater than free cells in simulated gastrointestinal conditions.

Future work should involve further optimisation of the microencapsulation process, since a significant loss of cell count was still evident with the microencapsulated formulation. Additional characterisation of a final formulation, in terms of the mechanisms of action and safety of the probiotic strain, the produced FA, and the use of the microencapsulation with in vitro and in vivo studies should be performed. In terms of the gastrointestinal tract, FAE activity should be characterized in vivo in appropriate animal models to ensure enzyme activity remains stable and efficient under potentially harsh conditions. The fate of the APA microcapsule should also be investigated in vivo. This work, nonetheless, opens up future potentials for the use of a synergistic formulation of microencapsulated L. fermentum NCIMB 5221 with its intrinsic microbial FAE activity for both industrial and therapeutic applications.

\section{Acknowledgments}

The authors would like to acknowledge Micropharma Limited grants and a Canadian Institute of Health Research (CIHR) grant (MOP 264308) to Satya Prakash, the support of the Industrial Innovation Scholarship (IIS) BMP Innovation - NSERC, FQRNT and Micropharma Limited to Catherine Tomaro-Duchesneau, a FRSQ Master's award to Michael Coussa-Charley and a FRSQ Doctoral award to Meenakshi Malhotra.

\section{Conflict of Interest}

The authors declare that no financial support or other compensation has been received relating to any aspect of this research or its publication that could be construed as a potential conflict of interest. 


\section{References}

1. Rice-Evans, C.A.; Miller, N.J.; Paganga, G. Structure-antioxidant activity relationships of flavonoids and phenolic acids. Free Radic. Biol. Med. 1996, 20, 933-956.

2. Lombard, D.B.; Chua, K.F.; Mostoslavsky, R.; Franco, S.; Gostissa, M.; Alt, F.W. DNA Repair, Genome Stability, and Aging. Cell 2005, 120, 497-512.

3. Kampa, M.; Alexaki, V.-I.; Notas, G.; Nifli, A.-P.; Nistikaki, A.; Hatzoglou, A.; Bakogeorgou, E.; Kouimtzoglou, E.; Blekas, G.; Boskou, D.; et al. Antiproliferative and apoptotic effects of selective phenolic acids on T47D human breast cancer cells: Potential mechanisms of action. Breast Canacer Res. 2003, 6, R63-R74.

4. Chang, C.J.; Chiu, J.H.; Tseng, L.M.; Chang, C.H.; Chien, T.M.; Wu, C.W.; Lui, W.Y. Modulation of HER2 expression by ferulic acid on human breast cancer MCF7 cells. Eur. J. Clin. Investig. 2006, 36, 588-596.

5. Lee, Y. Role of NADPH oxidase-mediated generation of reactive oxygen species in the mechanism of apoptosis induced by phenolic acids in HepG2 human hepatoma cells. Arch. Pharm. Res. 2005, 28, 1183-1189.

6. Taniguchi, H.; Hosoda, A.; Tsuno, T.; Maruta, Y.; Nomura, E. Preparation of ferulic acid and its application for the synthesis of cancer chemopreventive agents. Anticancer Res. 1999, 19, 3757-3761.

7. Lesca, P. Protective effects of ellagic acid and other plant phenols on benzo[a]pyrene-induced neoplasia in mice. Carcinogenesis 1983, 4, 1651-1653.

8. Tanaka, T.; Kojima, T.; Kawamori, T.; Wang, A.; Suzui, M.; Okamoto, K.; Mori, H. Inhibition of 4-nitroquinoline-1-oxide-induced rat tongue carcinogenesis by the naturally occurring plant phenolics caffeic, ellagic, chlorogenic and ferulic acids. Carcinogenesis 1993, 14, 1321-1325.

9. Zhao, Z.; Egashira, Y.; Sanada, H. Digestion and absorption of ferulic acid sugar esters in rat gastrointestinal tract. J. Agric. Food Chem. 2003, 51, 5534-5539.

10. Spencer, J.P.E.; Chowrimootoo, G.; Choudhury, R.; Debnam, E.S.; Srai, S.K.; Rice-Evans, C. The small intestine can both absorb and glucuronidate luminal flavonoids. FEBS Lett. 1999, 458, 224-230.

11. Bhathena, J.; Martoni, C.; Kumar, A.; Urbanska, A.; Malhotra, M.; Prakash, S. Orally delivered microencapsulated live probiotic formulation lowers serum lipids in hypercholesterolemic hamsters. J. Med. Food 2009, 12, 310-319.

12. Tomaro-Duchesneau, C.; Saha, S.; Malhotra, M.; Coussa-Charley, M.; Al-Salami, H.; Jones, M.L.; Labbé, A.; Prakash, S. Lactobacillus fermentum NCIMB 5221 has a greater ferulic acid production compared to other ferulic acid esterase producing Lactobacilli. Int. J. Probiotics Prebiotics 2012, 7, in press.

13. Prakash, S.; Tomaro-Duchesneau, C.; Saha, S.; Cantor, A. The gut microbiota and human health with an emphasis on the use of microencapsulated bacterial cells. J. Biomed. Biotechnol. 2011, 2011, doi:10.1155/2011/981214.

14. Poncelet, D. Microencapsulation: Fundamentals, methods and applications. In Surface Chemistry in Biomedical and Environmental Science; Blitz, J.P., Gun'ko, V.M., Eds; Springer: Dordrecht, The Netherlands, 2006; pp. 23-34. 
15. Chang, T.; Prakash, S. Procedures for microencapsulation of enzymes, cells and genetically engineered microorganisms. Mol. Biotechnol. 2001, 17, 249-260.

16. Mastihuba, V.; Kremnicky, L.; Mastihubova, M.; Willett, J.L.; Cote, G.L. A spectrophotometric assay for feruloyl esterases. Anal. Biochem. 2002, 309, 96-101.

17. U.S. Pharmacopeia. Test Solutions. 2010.

18. Prakash, S.; Rodes, L.; Coussa-Charley, M.; Tomaro-Duchesneau, C. Gut microbiota: Next frontier in understanding human health and development of biotherapeutics. Biol. Targets Ther. 2011, 2011, 71-86.

19. FAO and WHO. Health and Nutritional Properties of Probiotics in Food Including Powder Milk with Live Lactic Acid Bacteria; Food and Agricultural Organization of the United Nations: Cordoba, Argentina, 1-4 October 2001.

20. Branton, W.B.; Jones, M.L.; Tomaro-Duchesneau, C.; Martoni, C.J.; Prakash, S. In vitro characterization and safety of the probiotic strain Lactobacillus reuteri Cardioviva NCIMB 30242. Int. J. Probiotics Prebiotics 2011, 6, 1-12.

21. Wolvers, D.; Antoine, J.M.; Myllyluoma, E.; Schrezenmeir, J.; Szajewska, H.; Rijkers, G.T. Guidance for substantiating the evidence for beneficial effects of probiotics: Prevention and management of infections by probiotics. J. Nutr. 2010, 140, 698S-712S.

22. Jankovic, I.; Sybesma, W.; Phothirath, P.; Ananta, E.; Mercenier, A. Application of probiotics in food products - challenges and new approaches. Curr. Opin. Biotechnol. 2010, 21, 175-181.

23. Floch, M.H. Probiotic therapy for ulcerative colitis. J. Clin. Gastroenterol. 2010, 44, 237-238.

24. Al-Salami, H.; Butt, G.; Fawcett, J.; Tucker, I.; Golocorbin-Kon, S.; Mikov, M. Probiotic treatment reduces blood glucose levels and increases systemic absorption of gliclazide in diabetic rats. Eur. J. Drug Metab. Pharmacokinet. 2008, 33, 101-106.

25. Luoto, R.; Laitinen, K.; Nermes, M.; Isolauri, E. Impact of maternal probiotic-supplemented dietary counselling on pregnancy outcome and prenatal and postnatal growth: A double-blind, placebo-controlled study. Br. J. Nutr. 2010, 103, 1792-1799.

26. Azcarate-Peril, M.A.; Altermann, E.; Hoover-Fitzula, R.L.; Cano, R.J.; Klaenhammer, T.R. Identification and inactivation of genetic loci involved with Lactobacillus acidophilus acid tolerance. Appl. Environ. Microbiol. 2004, 70, 5315-5322.

27. Guglielmetti, S.; de Noni, I.; Caracciolo, F.; Molinari, F.; Parini, C.; Mora, D. Bacterial cinnamoyl esterase activity screening for the production of a novel functional food product. Appl. Environ. Microbiol. 2008, 74, 1284-1288.

28. Mates, J.M.; Perez-Gomez, C.; de Castro, I.N.; Asenjo, M.; Marquez, J. Glutamine and its relationship with intracellular redox status, oxidative stress and cell proliferation/death. Int. J. Biochem. Cell Biol. 2002, 34, 439-458.

29. Martoni, C.; Bhathena, J.; Urbanska, A.M.; Prakash, S. Microencapsulated bile salt hydrolase producing Lactobacillus reuteri for oral targeted delivery in the gastrointestinal tract. Appl. Microbiol. Biotechnol. 2008, 81, 225-233.

30. Christopher, M.; Jasmine, B.; Mitchell Lawrence, J.; Aleksandra Malgorzata, U.; Hongmei, C.; Satya, P. Investigation of microencapsulated BSH active Lactobacillus in the simulated human GI tract. J. Biomed. Biotechnol. 2007, doi:10.1155/2007/13684. 
31. Tanaka, H.; Doesburg, K.; Iwasaki, T.; Mierau, I. Screening of lactic acid bacteria for bile salt hydrolase activity. J. Dairy Sci. 1999, 82, 2530-2535.

32. Pfeiler, E.A.; Klaenhammer, T.R. Role of transporter proteins in bile tolerance of Lactobacillus acidophilus. Appl. Environ. Microbiol. 2009, 75, 6013-6016.

33. Srinivasan, M.; Sudheer, A.R.; Menon, V.P. Ferulic acid: Therapeutic potential through its antioxidant property. J. Clin. Biochem. Nutr. 2007, 40, 92-100.

34. Adisakwattana, S.; Moonsan, P.; Yibchok-anun, S. Insulin-releasing properties of a series of cinnamic acid derivatives in vitro and in vivo. J. Agric. Food Chem. 2008, 56, 7838-7844.

35. Sri Balasubashini, M.; Rukkumani, R.; Menon, V.P. Protective effects of ferulic acid on hyperlipidemic diabetic rats. Acta Diabetol. 2003, 40, 118-122.

36. Balasubashini, M.S.; Rukkumani, R.; Viswanathan, P.; Menon, V.P. Ferulic acid alleviates lipid peroxidation in diabetic rats. Phytother. Res. 2004, 18, 310-314.

37. Atsuyo, F.; Hideyuki, S.; Asako, D.; Kunihisa, O.; Shohei, M.; Hiroto, F.; Masahiro, N.; Taisei, N.; Takuo, T.; Hisaji, T.; et al. Ferulic acid prevents pathological and functional abnormalities of the kidney in Otsuka Long-Evans Tokushima Fatty diabetic rats. Diabetes Res. Clin. Pract. 2008, 79, 11-17.

38. Bhathena, J.; Kulamarva, A.; Martoni, C.; Urbanska, A.M.; Prakash, S. Preparation and in vitro analysis of microencapsulated live Lactobacillus fermentum 11976 for augmentation of feruloyl esterase in the gastrointestinal tract. Biotechnol. Appl. Biochem. 2008, 50, 1-9.

39. Kailasapathy, K. Survival of free and encapsulated probiotic bacteria and their effect on the sensory properties of yoghurt. LWT - Food Sci. Technol. 2006, 39, 1221-1227.

(C) 2012 by the authors; licensee MDPI, Basel, Switzerland. This article is an open access article distributed under the terms and conditions of the Creative Commons Attribution license (http://creativecommons.org/licenses/by/3.0/). 